\title{
Assessment of the attitude towards childbirth in health sciences students - development and validation of the questionnaire Cave-St
}

\author{
Ernesto González-Mesa ${ }^{1,2}$ (D) Cristóbal Rengel-Díaz ${ }^{3,4}$ (D) Olga Riklikiene $^{5}$ (I) $\cdot$ Gilliam Thomson $^{6,7}$ (D)

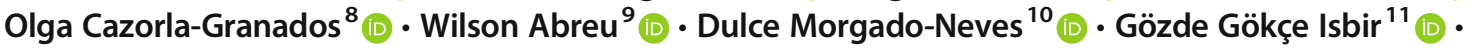 \\ Sigríour Sia Jonsdottir ${ }^{12}$ (D) $\cdot$ Sigfríour Inga Karlsdóttir ${ }^{12}$ (D) Joan Lalor $^{13}$ (D)
}

Accepted: 19 May 2021 / Published online: 5 June 2021

(C) The Author(s) 2021

\begin{abstract}
The purpose of this study is to report on the validation process of a questionnaire that explores health science students' attitudes towards women's childbirth experiences. This questionnaire can help inform education programs to enhance the quality of woman-professional interactions, and to improve women's experiences of childbirth. A standardized procedure for the development and validation of the questionnaire included: item development and psychometric pre-validation, Cronbach's Alpha coefficient calculation, test-retest and item-total correlation for the reliability analysis. Content validity was undertaken by Delphi method with sixteen panelists over two rounds. We determined the factor structure and refined and validated the questionnaire according to the responses of a cohort of 560 students using principal components factor analysis with varimax rotation. Confirmatory factor analysis was undertaken. A 52-items questionnaire CAVE-st: (acronym for cuestionario de actitudes sobre vivencias y experiencias en el parto) was developed and validated. The results of the factor analysis finally revealed four latent dimensions. The questionnaire CAVE-st is a valid and reliable tool to assess health science students' attitude towards women's childbirth experiences. Further work to translate and adapt the instrument in other cultures and languages will be undertaken.
\end{abstract}

Keywords CAVE-st · Childbirth · Perinatal education · Questionnaire development · Students'attitude

\section{Background}

In the experience of childbirth, aside from women being provided with insights into objective complications, women's perception of the verbal and non-verbal behaviors that health

Ernesto González-Mesa

egonzalezmesa@uma.es

1 School of Medicine, Obstetrics and Gynecology Department, Universityof Malaga, 32nd Louis Pasteur Boulevard, 29071 Málaga, Spain

2 IR Grupo IBIMA de investigación en Medicina Maternofetal, epigenética, enfermedades de lamujer y salud reproductiva, CGP Alameda, Hospital Regional Universitario SSPA de Málaga, Malaga, Spain

3 Faculty of Health Sciences, University of Malaga, Malaga, Spain

4 Hospital Universitario Virgen de la Victoria de Málaga, Grupo IBIMA de investigación en medicina maternofetal, epigenética, enfermedades de la mujer y salud reproductiva, Malaga, Spain

5 Nursing and Care Department, Faculty of Nursing, Lithuanian University of Health Sciences, Kaunas, Lithuania care providers display impacts on their experience of pregnancy and childbirth (Sorenson \& Tschetter, 2010). A growing body of research reports that inadequate-sometimes disrespectful, abusive or even violent - care during pregnancy, childbirth or the postpartum period are specific risk factors

6 Perinatal Health, School of Community Health and Midwifery, University of Central Lancashire, Lancashire, UK

7 School of Education, Health and Social Studies, Dalarna University, Falun, Sweden

8 School of Psychology, Universidad Nacional de Educación a Distancia, Málaga, Spain

9 Porto School of Nursing, CINTESIS (University of Porto), Porto, Portugal

10 Instituto Universitário de Lisboa (ISCTEIUL), Centro de Investigação e Estudos de Sociologia, Lisbon, Portugal

11 Midwifery Department, Mersin University, Mersin, Turkey

12 School of Health Sciences, University of Akureyri, Akureyri, Iceland

13 School of Nursing \& Midwifery, Trinity College Dublin, University of Dublin, Dublin, Ireland 
for birth-related trauma (Afulani \& Moyer, 2019; Meaney et al., 2016; Sando et al., 2017; Simpson \& Catling, 2016). Many women remember childbirth as an adverse event, between 10 and $48 \%$ recall it as a traumatic event, and $1-6 \%$ go on to develop post-traumatic stress disorder (Beck, 2004; Ford \& Ayers, 2011; Rijnders et al., 2008; Stramrood et al., 2011; Yildiz et al., 2017); with poor interactions with care providers identified as a key cause of women's frustration and psychological distress (Simpson \& Catling, 2016).

While some variables related to women's negative experiences of childbirth, are often of unknown and unpredictable etiology, those related to interpersonal interactions with health professionals are modifiable, and can be improved (O'Connell, 2019). The potential influence of education programs challenges perinatal health educators on how to contribute to solving the problem (Stoll et al., 2009; Watanabe et al., 2012). The matter is that while methods to teach clinical and technical skills into the physiology and physiopathology of pregnancy and childbirth are generally straightforward, how to improve the quality of woman-provider interactions is less developed.

Some authors have reported the need to include specific learning in dignity and respect in undergraduate midwifery programs (Hall \& Mitchell, 2016); some others highlighted the lack of standardized curricula in ethics and professionalism in neonatal or maternal-fetal fellowship programs (Arzuaga \& Cummings, 2016; Cummings et al., 2015). Also, the difficulties that Obstetrics and Gynecology residents have to identify women's psychiatric needs (Garbarino et al., 2019), and the necessity to overcome the barriers in maternalchild education (Drake, 2016) have been claimed. In the structure of perinatal education programs the domain 'Professional quality' has to be the basis of other domains, regarding pregnancy as normal physical process and advocating and supporting natural birth (Yin et al., 2018). Graduate and postgraduate health science students need to acquire clinical skills, as well as interpersonal skills that include how to provide empathic, dignified and respectful care with pregnant and postnatal women (Petit-Steeghs et al., 2019; Warren et al., 2018).

The need to improve the education and training programs of future professionals has been pointed out by institutions like the World Health Organization as a means to improve perinatal care and reduce obstetric traumas (World Health Organization, 2015).

The evaluation of the students' attitude towards childbirth, can help to know the areas that teaching programs need to improve in order to promote a better care and a positive childbirth experience (Downe et al., 2018; Renfrew et al., 2014; Warren et al., 2018). Current good clinical practice guidelines for quality maternal and neonatal care, together with the authors' clinical experience, have been used to define the attitudes that perinatal educational programs should promote in the students as future delivery-room-professionals: a combination of clinical knowledge and skills with interpersonal and cultural competence, aimed at optimizing biological, psychological and psychosocial processes, strengthening women's capabilities and using medical interventions only when indicated (Renfrew et al., 2014).

The aim of this study was to report on the validation process of a questionnaire to explore graduate and postgraduate health sciences students (nursing, midwifery, obstetrics, paediatrics, etc) attitudes towards women's childbirth experiences. The questionnaire will become an useful tool to identify which areas of psychosocial care need to be improved in the perinatal syllabus, to promote better care for women at childbirth. Also, it will help to evaluate the effectiveness of any educational intervention.

\section{Methodology}

For the development and validation of the questionnaire we have followed five consecutive steps. Firstly, the tool was conceptualized and the initial selection of the items was made. In the second phase, a group of independent experts evaluated the relevance, clarity and coherence of the items to purify the questionnaire using the Delphi methodology. In the third phase, a pilot test was carried out in a group of students in order to identify either formal or conceptual difficulties. In the fourth phase, the psychometric evaluation of the scale was carried out and the questionnaire was refined. Finally, in the fifth phase, an exploratory and confirmatory factor analysis was carried out. Figure 1 shows the flow diagram for the development and validation process of the questionnaire.

\section{Questionnaire Development}

As there was no existing questionnaire in this area, we consulted with academics and clinicians from various European universities (Spain, Iceland, Lithuania, Portugal, Turkey and UK) and fields, such as nursing, midwifery, psychology, anthropology, medicine and perinatal care. They/the group proposed a total of 100 items for the new instrument. These items were considered to define the attitudes that perinatal students should have at the end of their programs as future delivery-room-professionals. The selection of items was based on current published literature, best practice guidelines in childbirth care (Downe et al., 2018; Renfrew et al., 2014; Warren et al., 2018; World Health Organization, 2015), and experts' professional and academic backgrounds. Firstly, a series of brainstorming e-mails were exchanged to add, remove, discuss or change the items. Also, two virtual meetings were held to complete the list of one-hundred items.

The items covered the cognitive, behavioral, and affective components of students' attitudes towards childbirth, 
Fig. 1 Flow diagram for development and validation of CAVE st

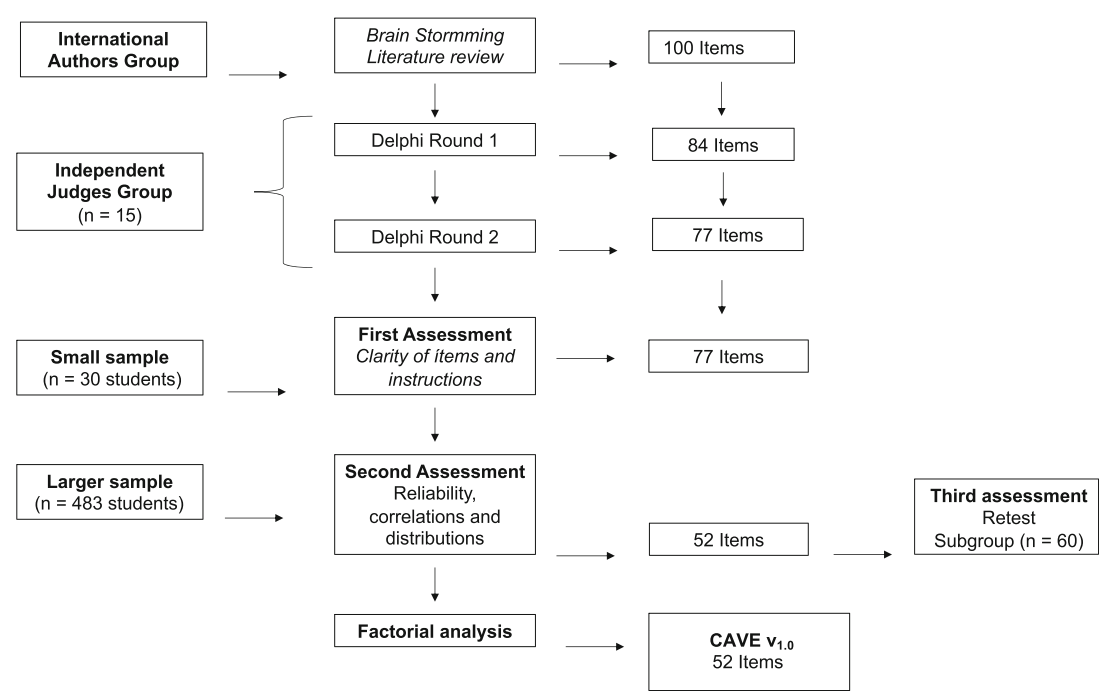

corresponding to some of these previously proposed key categories: cognitions (knowledge about care and attention during normal childbirth, beliefs about pain during delivery, priorities related to fetal and maternal health balance, ability to identify birth-related trauma), behaviors (authority distribution in the delivery-room, support during delivery, professional interactions with laboring women including authorization to intervene, respecting women's decisions, respecting women's physiology and the need to identify oneself as a student), and emotions (feelings towards the mother during labour, and towards normal childbirth or obstetric trauma).

\section{Delphi Method}

A consensus Delphi approach was used to validate the 100items-questionnaire (Jones \& Hunter, 1995; Murphy et al., 1998). A different panel of experts from multi-professional backgrounds were appointed to analyze the coherence, clarity and relevance of the proposed items, and to suggest other relevant items that had not been considered. The panel comprised sixteen professionals, including psychiatrists, psychologists, nurses, midwives and gynaecologists, who were of different ages, and from different regions of Spain. All the professionals had a teaching or clinical profile, or both, and all were professionally active.

An online questionnaire was developed, with experts asked to rate all the initial items $(n=100)$ using 5 point Likert scales of strongly disagree/not relevant at all, disagree/not relevant, neutral, agree/relevant, strongly agree/very much relevant. Two rounds of anonymous questionnaires were shared; after the first round, information was provided on the overall results, with experts then asked to rate the list of questions again. Any item which received $80 \%$ agreement for coherence, clarity and relevance were retained. In both rounds the experts were allowed to add any comment regarding either the items or the questionnaire. Content validity index was calculated for individual items and for the scale (available as supplementary file 1).

\section{Pilot Study}

Further means to assess the clarity of the questions and quesversion of the questionnaire tested on a small group of students $(n=30)$. The students were asked to complete the questionnaire and give us written feed-back about the understandability of the items. They were encouraged to comment on any aspects regarding either the design of the questionnaire or its content.

\section{Psychometric Assessment and Refinement of the Scale}

Once the questionnaire prototype was completed, the next step was a field test with a larger sample group. All the final-cycle students of the degree in medicine at the University of Malaga $(N=560)$ were invited to participate via an internet link to the questionnaire. The Cronbach's alpha and Gutman's split-half coefficients were used to measure the internal consistency of the scoring of the questionnaire. The ceiling and floor effects were checked, and the items that reduced the overall consistency were excluded. The reliability of the instrument was undertaken inviting the students to complete the online questionnaire twice, at 14 days apart, and the intraclass correlation index was calculated.

\section{Exploratory and Confirmatory Factorial Analysis}

The Kaisser-Meyer-Olkin (KMO) test and the Barlett's test of sphericity were performed to assess the adequacy of an exploratory factor analysis. An exploratory first- and secondorder factor analysis were then conducted using the analysis tionnaire instructions was also undertaken, with an on-line 
of the principal components of the scale, and the Varimax rotation method was used to identify latent factors that explained the observed variance. Structural Equation Modelling (SEM) analyses with correlated factors were tested using the maximum likelihood robust estimator. Four fit indices were selected a priori to assess model fit: comparative fit index (CFI), Tucker-Lewis index (TLI), Standardized Root Mean Square (SRMS), and Root Mean Square error of Approximation (RMSEA). Acceptable model fit was defined by a CFI $\geq .90$, Tucker-Lewis index $\geq .90$, SRMR or RMSEA values $\leq .08$ (Bentler, 1990)'(Hu \& Bentler, 1999). Based on these criteria, the best fitting final model was selected.

\section{Ethics}

Prior authorization to issue the questionnaire to students was obtained from the ethics committee at Comité de Ética de de la Investigación de la provincial de Málaga (Code CAVE-st001-2020). When opening the link to the questionnaire, participants were provided with information about the aims and purpose of the study, and how privacy, anonymity, and confidentiality was ensured. Participants were asked to check a box to indicate their consent to participate.

\section{Results}

The results will be described below.

\section{Outcomes from the Delphi Method}

Among the group of sixteen experts that took part in the Delphi method, there were twelve women $(75 \%)$, and four men. (25\%) Six of them were midwives $(37.5 \%)$, while two were nurses $(12.5 \%)$, five obstetricians $(41.6 \%)$, two psychologists $(12.5 \%)$, and one psychiatrist $(6.2 \%)$. Eleven had active clinical practice in maternity hospitals $(68.7 \%)$, and one in primary care $(6.2 \%)$, while four of them were university teachers $(25 \%)$. During the first round sixteen items were eliminated as they were not considered relevant, clear or coherent by $\geq 80 \%$ of the experts. The average levels of agreement were $80.6 \%$ for clarity, $81.6 \%$ for relevance, and $93.5 \%$ for coherence in first round. In the second round the agreement was $81.0 \%$ for clarity, $89.7 \%$ for relevance, and $93.7 \%$ for coherence. After the second round, seven more items that did not reach at least an $80 \%$ of agreement among the experts, were eliminated, and also, the wording of a further four were improved as per the experts' recommendations. Finally, a set of 77 items was obtained. The overall Scale CVI agreement was .88 for clarity, .94 for relevance and .94 for coherence. Supplementary file 1 shows the S-CVI and I-CVI scores.

\section{Outcomes from the Pilot Study}

In order to detect problems of interpretation of the prototype and to assess the understanding of the questions and the included instructions, an online version was piloted with 30 participants (students). Overall feedback was very positive regarding the length and wording of the items, and no comprehension problems were reported.

\section{Psychometric Assessment}

The prototype was issued to a sample of 560 students, of whom 483 completed the questionnaire (response rate of $86.25 \%$ ). The average age of the students was 23.9 years, ranging from 23 to 37 year-old $(S D=2.0)$, most of them were women $(71.5 \%)$ and only seven of them had been pregnant and had children. The internal consistency of the 77 -item prototype obtained a Cronbach's alpha of .80 and a Gutman's split half coefficient of .72 . The item reduction was driven based on statistical criteria, in order to increase consistency (alpha) and parsimony, by eliminating the items that clearly reduced alpha, so that we got a more parsimonious tool with a more manageable number of items. Analysis of the correlations between the items and the overall score produced a final 52-item scale, called CAVE-st (acronym for cuestionario de actitudes sobre vivencias y experiencias en el parto), with an improved Cronbach's alpha of 89 .

The final 52-item version of CAVE-st asked participants to rate their agreement between 1 (completely disagree) and 5 (completely agree) to positively framed questions (item 4, 9, $11-15,17,20,21,24-45,49,51,52)$ and between 1 (completely agree) and 5 (completely disagree) to negatively framed questions (item 1-3, 5-8, 10, 16, 18, 19, 22, 23, 4648, 50). The final CAVE-st score ranges between 52 and 260 .

The mean, median and mode scores, the standard deviation and 25th, 50th and 75th percentiles from the sample have been included as supplementary material (file-2). We did not find differences according to the age or gender of respondents.

Finally, the test-retest reliability was assessed in a sample of 60 students with a further copy of the questionnaire completed two weeks after it was first completed. A Spearman correlation index $\mathrm{r}=.73, p<.001$ and a significant intraclass correlation coefficient $\mathrm{r}=.86, p<.001$ confirmed its reliability.

\section{Factorial Analysis}

The Kaiser-Meyer-Olkin measure was .86 and the Bartlett's test of sphericity was favourable $\left(X^{2}(1326, N=52)=\right.$ 9525.73, $p<.001)$. The exploratory factory analysis initially revealed sixteen components that explained $63.67 \%$ of the variance (supplementary file-2, Table 1). While one of the components (Component 1) explained $19.46 \%$ of the total 
Table 1 Second order exploratory factor analysis

\begin{tabular}{|c|c|c|c|c|c|c|}
\hline & \multicolumn{3}{|c|}{ Initial Eigenvalues } & \multicolumn{3}{|c|}{ Rotation sums of squared loadings } \\
\hline & Total & $\%$ of Variance & Cumulative $\%$ & Total & $\%$ of Variance & Cumulative $\%$ \\
\hline L 1 & 4,5 & 31,9 & 31,9 & 2,7 & 19,3 & 19,3 \\
\hline L 2 & 1,4 & 9,8 & 41,6 & 1,9 & 13,9 & 33,1 \\
\hline L 3 & 1,2 & 8,3 & 49,9 & 1,9 & 13,5 & 46,7 \\
\hline L 4 & 1,1 & 7,6 & 57,5 & 1,5 & 10,8 & 57,5 \\
\hline
\end{tabular}

L1, obstacles for a positive childbirth; L2, interpersonal Interaction; L3, women's needs; L4, authority distribution during childbirth variance, the rest of the 15 components ranged between $6.4 \%$ and $1.8 \%$. Tables showing the proportion of the total variance explained by each main component, the distribution of items and their saturation in each component have been included as supplementary material (Supplementary file-2, Tables 1 and 2). Components 1 to 16 were defined by a different number of items, with the range from 1 to 8 items. It worth's mentioning that components 15 and 16 only included 1 item each. In component 15 the item assessed the role of birth trauma as a risk factor for breastfeeding difficulties, in component 16 , the item assessed student's attitudes towards continuous cardiotocography during normal childbirth. After the analysis, and following logical and clinical criteria, these single items from components 15 and 16, were added to components 7 and 11 respectively, in which they also showed acceptable saturation coefficients.
In order to put a structure on the pattern of covariance between these fourteen first-order factors and to explain the covariance in a more parsimonious way with fewer parameters, we hypothesized that some other higher order factors accounted for the pattern of relations between the first-order factors, performing a second-order exploratory factor analysis. The Kaiser-Meyer-Olkin statistic in this case was .85 and the Bartlett's test of sphericity was also favorable for the EFA $\left(X^{2}\right.$ $(91, N=16)=1750.81, p<.001)$. We found that four latent second-order factors accounted for the $57.5 \%$ of the total variance as it is shown in Table 1. The scree plot, the distribution of items in each second order latent factor, the saturation coefficients, and the main statistics for their scores are available as supplementary material (file-2, Tables 3-4 and Fig. 2). According to their items composition the four factors were related to students' opinion about the main obstacles for a
Table 2 Structural equation model indices

\begin{tabular}{lll}
\hline Fit statistic & Value & Description \\
\hline Likelihood ratio & 78.73 & \\
chi2_ms(61) & .06 & model vs. saturated \\
p $>$ chi2 & & \\
Population error & .04 & Root mean squared error of approximation \\
RMSEA & $90 \%$ CI $[.00-.06]$ & \\
p close & .64 & Probability RMSEA $<=0.05$ \\
Information criteria & 8779.95 & \\
AIC & 8956.84 & Akaike's information criterion \\
BIC & & Bayesian information criterion \\
Baseline comparison & .94 & Comparative fit index \\
CFI & .92 & Tucker-Lewis index \\
TLI & & \\
Size of residuals & .05 & Standardized root mean squared residual \\
SRMR & .96 & Coefficient of determination \\
CD &
\end{tabular}

RMSEA, root mean squared error of approximation; SRMR, standardized root mean square residual; $C F I$, Comparative fit index; AIC, Akaike's information criterion; TLI, Tucker-Lewis index; BIC, Bayesian information criterion; SRMR, Standardized root mean squared residual; $C D$, Coefficient of determination 
Fig. 2 Structural equation model. Factor 1, Psychosocial Factors; Factor 2, Women's empowerment; Factor 3, Role identity; Factor 4, Complications; Factor 5, Unexpected outcomes; Factor 6, Women's expectations; Factor 7, Obstetric Trauma;

Factor 8, Accompaniment; Factor 9, Empathy; Factor 10, Decision making; Factor 11,

Medicalization; Factor 12, Commitment; Factor 13, Respect; Factor 14, Clinical priorities; L1, obstacles for a positive childbirth; L2, interpersonal Interaction ; L3, women's needs; L4, authority distribution during childbirth

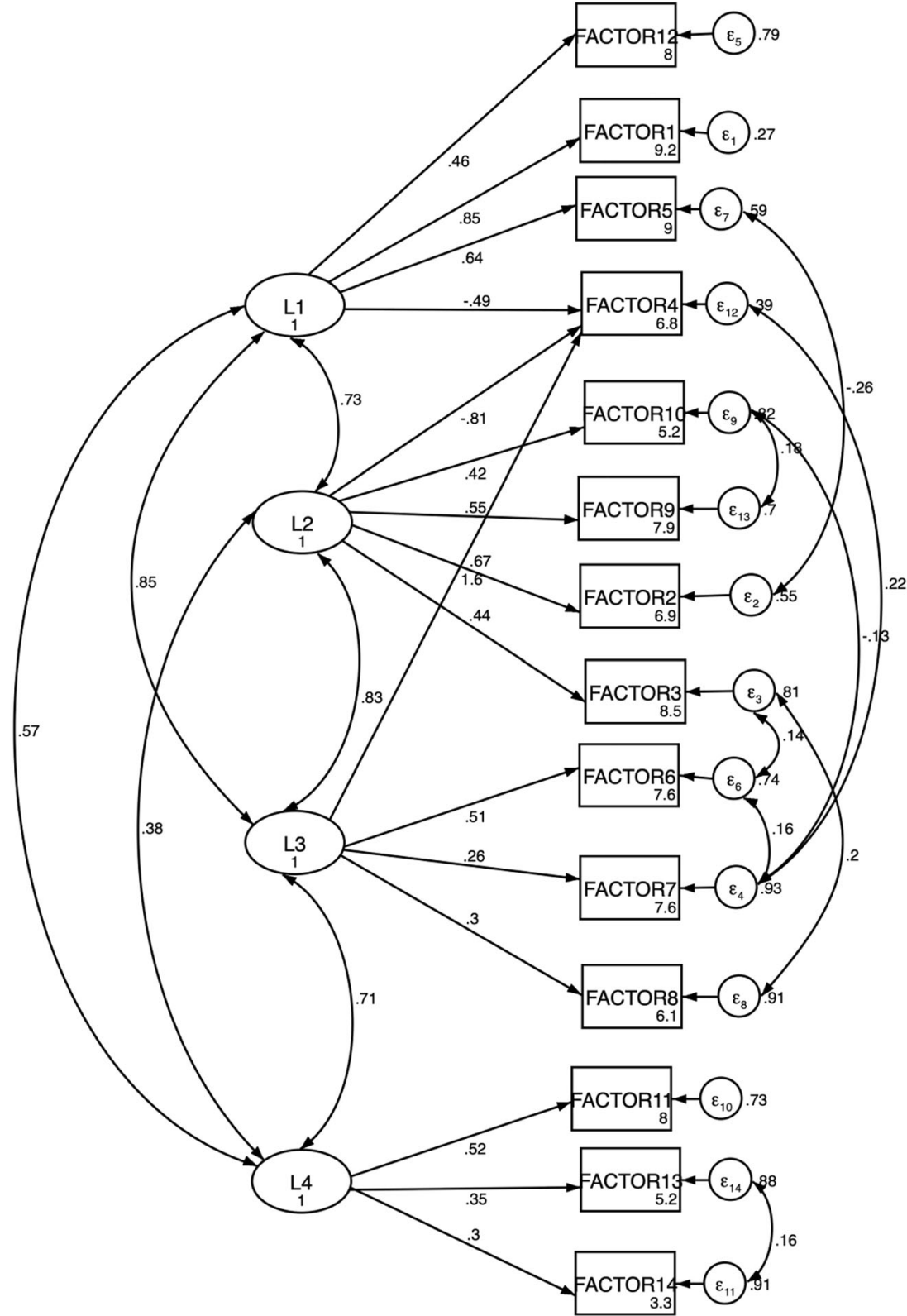

positive childbirth experience (L1), interpersonal Interactions during childbirth (L2), opinion about women's needs (L3), and authority distribution during childbirth (L4).

L1 comprises 22 items, and explores the position of the student about some possibly perceived barriers for a positive childbirth. It assesses the students' knowledge and opinion about the issues that could prevent childbirth from becoming a positive experience, such as poor obstetric or neonatal outcomes, medical complications, women's physical and mental health status, psychosocial risk factors, as well as the student's ability to identify potentially traumatic situations. L2 has 11 items, and gathers information about Interpersonal interaction. It explores the students' thoughts about her direct interaction with the women at childbirth, the need to ask for her consent to perform any intervention, to properly empathize with women and to identify themselves as students. L3 factor comprises 9 items and it gathers the information on the student's position regarding the needs that women can have during childbirth. Specifically, it explores their opinion about women's expectations, the need for accompaniment, as well as the importance of attending some other cultural or emotional needs. This factor includes a question regarding the influence of birth experience for an adequate establishment of breastfeeding. Finally, L4 has 10 items and it gathers information about the distribution of authority during childbirth. It explores the authoritarian bias received in their training, assessing the students' knowledge and beliefs about the medicalization of delivery care, obstetric violence, and their ability to adequately prioritize care needs in the delivery room. 
The confirmatory factor analysis was performed, and the structural equation modelling analyses confirmed the goodness of fit of this four-factors model as shown in Table 2 . The model was represented as shown in Fig. 2.

We did not find differences in scores according to the gender of the students, with the exception of L3 in which women scored significantly higher $(M=37.1, S D=3.3)$ than men $(M=35.3 .5, S D=4.1), t(154)=-2.71, p=.05$.

\section{Discussion}

This article describes the development and validation processes of CAVE-st, an instrument designed to measure health sciences students' attitudes towards childbirth. CAVE-st resulted in a 52-item questionnaire that were related to four major dimensions: Students' knowledge and opinion about what are the main obstacles for a positive experience (L1), development of interpersonal Interaction during childbirth (L2), opinion about women's needs (L3), and authority distribution during childbirth (L4). Structural model analysis has been performed showing the goodness of fit of the model. The evaluation of these components allows to know the attitude that students show towards childbirth, highlighting the suitability of the training received. The psychometric analyses revealed that CAVE-st is a reliable and valid tool to use in health science academic contexts.

Students' awareness of the main obstacles for a humanized childbirth (L1), is a critical point to start taking into account values such as woman's emotional state, beliefs, sense of dignity and autonomy in their future professional practice, in order to achieve the goal of promoting a positive childbirth experience (Behruzi, Hatem, Fraser, et al., 2010a; Wagner, 2001). A number of studies have been published in the last decade that explore incorporating specific competencies or pedagogical interventions in medical, nursing or midwifery study programs (Arzuaga \& Cummings, 2016; Cooksey, 2010; Cummings et al., 2015; Daboval et al., 2014, 2019; Drake, 2016; Garbarino et al., 2019; Hall \& Mitchell, 2016; Persson et al., 2018; Pilkenton et al., 2015; Shakartzi et al., 2018; Thompson et al., 2019; Yin et al., 2018). Most of these studies are surveys conducted among education experts and program directors, with particular attention to training needs in relation to dignity, respect (Hall \& Mitchell, 2016; Yin et al., 2018) and perinatal mental health (Garbarino et al., 2019). The quality of the interpersonal interaction with women at childbirth is another of the main factors included in CAVE-st (L2). Poor interpersonal interaction has been presented as one of the main risk factors for posttraumatic stress disorder after childbirth (Fenech \& Thomson, 2014), being advisable the inclusion in the perinatal training programs of competencies regarding the development of personal agency skills, persuasive and convincing communication skills, debate and discussion skills and reflexive practice as critical educational contents (Thompson et al., 2019). On the other hand, knowing to what extent the students are prepared to meet the expectations and cultural needs of women at childbirth (L3) highlights the possible effectiveness of training programs in the development of women centered maternities (Cooksey, 2010). Finally, some studies have shown that in situations where the needs and demands of the patients do not fit the biomedical model of disease (Dumit, 2006; Werner \& Malterud, 2003) the relationship becomes more difficult. When childbearing women want care or decline care that is not aligned with the recommendations of their care provider, this can cause tension, but women retain the right to respectful care. Students must know that they have to show respect to women's decisions, and concern for their expectations, without imposing their criteria (L4).

The CAVE-st questionnaire that we have developed and validated could be an useful tool to identify specific dimensions to target during the training, and a method to assess students' learning. It could also be useful to reveal educational needs in offering women individualized attention (LeonLarios et al., 2019), the meta-cognitive skills needed for effective communication (van Dinter-Douma et al., 2018), or the benefits of deepening the acquisition of reflective skills that could help students to be aware of their implicit knowledge and develop critical skills for decision-making (Kool et al., 2019). Self-reflection is essential to develop effective communication skills in challenging clinical situations, being an inherent component of learning from experience (Janssen et al., 2008). CAVE-st may also be useful to assess students' perception of risk in perinatal scenarios. Student's perception of risk or safety of the clinical situation can differ from the perspective of the woman, and also from other members of the care team. This is largely due to assessments being based on subjective, rather than objective and measurable indicators (de Melo-Martín \& Intemann, 2012). How students complete the questionnaire could thereby help to highlight how they value the need for implicit communication in determining the risks or certainties perceived by others (Lee et al., 2019) and the awareness of their own emotional responses. Also, our tool has the advantage of including the theoretical and practical aspects of birth related trauma and perinatal mental health (Coates \& Foureur, 2019; Garbarino et al., 2019; Hauck et al., 2015; Higgins et al., 2016; Noonan et al., 2018).

During labour and birth, humanity and compassion are essential elements of a woman's care, and especially in cases with complications (Berg, 2005). Many factors can hinder professionals' providing person-centred care (Behruzi, Hatem, Goulet, et al., 2010b) such as the need to protect the safety of the mother and the foetus, irrespective of a woman's preferred birthing choices. Efforts should be aimed at fostering environments in which, in addition to pursuing the best possible obstetric and perinatal outcomes, women feel in 
control of the situation, safe and respected (Fontein-Kuipers et al., 2018) For this purpose, CAVE-st may be an useful tool.

According to the results of the survey, we have learned that issues like taking women's opinions into account in the decision-making process during childbirth, knowing how to prioritize maternal and fetal needs in the delivery room, and avoiding unnecessary medicalization of labor, are some of the goals that our perinatal educational program needs to address. The tool that we have developed can be used either prospectively to learn about the specific needs of the students that access perinatal education programs or retrospectively to evaluate the attitudes of students who finish their perinatal program, in order to know the aspects that need to be improved to promote a more positive attitude towards childbirth. Also, it could also be useful to objectively evaluate the effect of a training interventions on the students' attitudes.

\section{Limitations and Strengths}

Some limitations need to be considered. First, as this is the first instrument to assess students' attitudes towards childbirth, we could not compare our results with any other published results. Second, the validation was based on the responses of a limited homogenous sample of medical students, rather than wider health science students which may have weakened the reported psychometric properties. Future assessments in larger samples including nursing and midwifery students will improve validation results.

The strengths are that the development and validation of CAVE-st followed systematic and standard procedures, with a Delphi consensus and three different assessments undertaken. The collaboration with international and multidisciplinary academics in the design and execution of this study also strengthens our findings.

\section{Conclusions}

This study provides detailed insights into the development and psychometric properties of the Cave-st questionnaire. Cave-st is the first questionnaire to assess health science students' attitudes of key factors that can impact on women's birth experiences. The results show that Cave-st is a valid and reliable tool and further work is planned to adapt and apply the instrument in other populations to capture international evidence. Cave-st can help identify what dimensions need to be integrated and reinforced in perinatal training programs, to compare variations in different pre-registration programs and in different settings, and ultimately to help design optimum training programs to improve women's experience of childbirth, and to avoid birth related trauma.
Supplementary Information The online version contains supplementary material available at https://doi.org/10.1007/s12144-021-01892-4.

Acknowledgements This study was carried out with the support of the COST Action - CA 18211: Perinatal Mental Health and Birth-Related Trauma: Maximising best practice and optimal outcomes. We appreciate the work of the expert group that participated in the Delphi panel, as well as the students that completed the assessments.

Authors' Contributions Conceptualization: EGM, CRD, SIK, OR, GT, WA, OCG, GGI. Methodology: EGM,CR, OR, WA, DMN, SIK, SSJ, GT, JL, GGI; Formal analysis and investigation: CRD, OCG, EGM, WA, DMN, GGI, GT, OR, SSJ, SIK; Writing - original draft preparation: EGM, CRD, OR, OCG, JL, SIK, GT, DMN, WA; Writing - review and editing: GT, JL, WA, OR, SIK,; Resources: CRD, EGM, OCG; Supervision: JL, OR, SIK, GT, WA, JL. CRD and EGM contributed equally, and both should be considered as first authors.

Availability of Data and Materials The datasets used and/or analysed during the current study are available from the corresponding author on reasonable request.

\section{Declarations}

Ethics Approval Ethical approval was obtained from CEI de la Provincia de Malaga.

Consent to Participate All the students participated voluntarily and gave their online written consent to participate.

Consent for Publication All authors agreed on the publication of this research.

Competing Interests Authors do not have any competing interest to declare.

Open Access This article is licensed under a Creative Commons Attribution 4.0 International License, which permits use, sharing, adaptation, distribution and reproduction in any medium or format, as long as you give appropriate credit to the original author(s) and the source, provide a link to the Creative Commons licence, and indicate if changes were made. The images or other third party material in this article are included in the article's Creative Commons licence, unless indicated otherwise in a credit line to the material. If material is not included in the article's Creative Commons licence and your intended use is not permitted by statutory regulation or exceeds the permitted use, you will need to obtain permission directly from the copyright holder. To view a copy of this licence, visit http://creativecommons.org/licenses/by/4.0/.

\section{References}

Afulani, P. A., \& Moyer, C. A. (2019). Accountability for respectful maternity care. In The Lancet, 394, 1692-1693. https://doi.org/10. 1016/S0140-6736(19)32258-5.

Arzuaga, B. H., \& Cummings, C. L. (2016). Practices and education surrounding anticipated periviable deliveries among neonatalperinatal medicine and maternal-fetal medicine fellowship programs. Journal of Perinatology, 36, 699-703. https://doi.org/10. 1038/jp.2016.68. 
Beck, C. T. (2004). Birth trauma: In the eye of the beholder. Nursing Research, 53, 28-35. https://doi.org/10.1097/00006199200401000-00005.

Behruzi, R., Hatem, M., Fraser, W., Goulet, L., Ii, M., \& Misago, C. (2010a). Facilitators and barriers in the humanization of childbirth practice in Japan. BMC Pregnancy and Childbirth, 10(1), 25. https:// doi.org/10.1186/1471-2393-10-25.

Behruzi, R., Hatem, M., Goulet, L., Fraser, W., Leduc, N., \& Misago, C. (2010b). Humanized birth in high risk pregnancy: Barriers and facilitating factors. Medicine, Health Care and Philosophy., 13, 4958. https://doi.org/10.1007/s11019-009-9220-0.

Bentler, P. M. (1990). Comparative fit indexes in structural models. Psychological Bulletin, 107(2), 238-246. https://doi.org/10.1037/ 0033-2909.107.2.238.

Berg, M. (2005). A midwifery model of care for childbearing women at high : Genuine caring in caring for the genuine. Journal of Perinatal Education. https://doi.org/10.1624/105812405x23577.

Coates, D., \& Foureur, M. (2019). The role and competence of midwives in supporting women with mental health concerns during the perinatal period: A scoping review. In Health and Social Care in the Community., 27, e389-e405. https://doi.org/10.1111/hsc.12740.

Cooksey, N. R. (2010). Bridging the gap between textbook and maternity : A nurse-developed teaching model for first-year medical students. Birth. https://doi.org/10.1111/j.1523-536X.2010.00428.x.

Cummings, C. L., Geis, G. M., Kesselheim, J. C., \& Sayeed, S. (2015). Ethics and professionalism education during neonatal-perinatal fellowship training in the United States. Journal of Perinatology, 35, 875-879. https://doi.org/10.1038/jp.2015.70.

Daboval, T., Ferretti, E., \& Moore, G. P. (2014). Innovative holistic teaching in a Canadian neonatal perinatal residency program. Hastings Center Report., 44, 21-25. https://doi.org/10.1002/hast. 384.

Daboval, T., Ferretti, E., Moussa, A., Van Manen, M., Moore, G. P., Srinivasan, G., Moldovan, A., Agarwal, A., \& Albersheim, S. (2019). Needs assessment of ethics and communication teaching for neonatal perinatal medicine programs in Canada. Paediatrics and Child Health (Canada)., 24, e116-e124. https://doi.org/10. 1093/pch/pxy108.

de Melo-Martín, I., \& Intemann, K. (2012). Interpreting evidence: Why values can matter as much as science. Perspectives in Biology and Medicine., 55, 59-70. https://doi.org/10.1353/pbm.2012.0007.

Downe, S., Finlayson, K., Oladapo, O., Bonet, M., \& Gülmezoglu, A. M. (2018). What matters to women during childbirth: A systematic qualitative review. In PLOS ONE., 13, e0194906. https://doi.org/ 10.1371/journal.pone.0194906.

Drake, E. (2016). Challenges and creative strategies in undergraduate nursing education in maternal-child health. Journal of Perinatal and Neonatal Nursing., 30, 179-183. https://doi.org/10.1097/JPN. 0000000000000188 .

Dumit, J. (2006). Illnesses you have to fight to get: Facts as forces in uncertain, emergent illnesses. Social Science and Medicine, 62(3), 577-590. https://doi.org/10.1016/j.socscimed.2005.06.018.

Fenech, G., \& Thomson, G. (2014). Tormented by ghosts from their past': A meta-synthesis to explore the psychosocial implications of a traumatic birth on maternal well-being. Midwifery., 30, 185-193. https://doi.org/10.1016/j.midw.2013.12.004.

Fontein-Kuipers, Y., Koster, D., Romijn, C., Sakko, E., Stam, C., Steenhuis, N., de Vries, D., \& Willigen, I. van. (2018). I-POEMS listening to the voices of women with a traumatic birth experience. Journal of Psychology and Cognition, 03(02). https://doi.org/10. 35841/psychology-cognition.3.2.29-36.

Ford, E., \& Ayers, S. (2011). Support during birth interacts with prior trauma and birth intervention to predict postnatal post-traumatic stress symptoms. Psychology and Health., 26, 1553-1570. https:// doi.org/10.1080/08870446.2010.533770.
Garbarino, A. H., Kohn, J. R., Coverdale, J. H., \& Kilpatrick, C. C. (2019). Current trends in psychiatric education among obstetrics and gynecology residency programs. Academic Psychiatry., 43, 294-299. https://doi.org/10.1007/s40596-019-01018-w.

Hall, J., \& Mitchell, M. (2016). Dignity and respect in midwifery education in the : A survey of Lead Midwives of Education. Nurse Education in Practice. https://doi.org/10.1016/j.nepr.2016.09.003.

Hauck, Y. L., Kelly, G., Dragovic, M., Butt, J., Whittaker, P., \& Badcock, J. C. (2015). Australian midwives knowledge, attitude and perceived learning needs around perinatal mental health. Midwifery., 31, 247255. https://doi.org/10.1016/j.midw.2014.09.002.

Higgins, A., Carroll, M., \& Sharek, D. (2016). Impact of perinatal mental health education on student midwives' knowledge, skills and attitudes: A pre/post evaluation of a module of study. Nurse Education Today, 36, 364-369. https://doi.org/10.1016/j.nedt.2015.09.007.

Hu, L. T., \& Bentler, P. M. (1999). Cutoff criteria for fit indexes in covariance structure analysis: Conventional criteria versus new alternatives. Structural Equation Modeling, 6(1), 1-55. https://doi. org/10.1080/10705519909540118.

Janssen, A. L., MacLeod, R. D., \& Walker, S. T. (2008). Recognition, reflection, and role models: Critical elements in education about care in medicine. Palliative and Supportive Care, 6(4), 389-395. https:// doi.org/10.1017/S1478951508000618.

Jones, J., \& Hunter, D. (1995). Consensus methods for medical and health services research. British Medical Journal., 33, 944-950. https://doi. org/10.2164/jandrol.111.015065.

Kool, L., Feijen-de Jong, E. I., Schellevis, F. G., \& Jaarsma, D. A. D. C. (2019). Perceived job demands and resources of newly qualified midwives working in primary care settings in the Netherlands. Midwifery, 69, 52-58. https://doi.org/10.1016/j.midw.2018.10.012.

Lee, S., Holden, D., Webb, R., \& Ayers, S. (2019). Pregnancy related risk perception in pregnant women, midwives \& doctors: A crosssectional survey. BMC Pregnancy and Childbirth., 19, 335. https://doi.org/10.1186/s12884-019-2467-4.

Leon-Larios, F., Nuno-Aguilar, C., Rocca-Ihenacho, L., Castro-Cardona, F., \& Escuriet, R. (2019). Challenging the status quo: Women's experiences of opting for a home birth in Andalucia, Spain. Midwifery., 70, 15-21. https://doi.org/10.1016/j.midw.2018.12.001.

Meaney, S., Lutomski, J. E., O'Connor, L., O’Donoghue, K., \& Greene, R. A. (2016). Women's experience of maternal morbidity: A qualitative analysis. BMC Pregnancy and Childbirth., 16, 184. https:// doi.org/10.1186/s12884-016-0974-0.

Murphy, B., Lamping, M. K., Sanderson, A., \& Marteau. (1998). Consensus development methods, and their use in clinical guideline development. Health Technology Assessment., 2. https://doi.org/10. 3310/hta2030.

Noonan, M., Doody, O., O’Regan, A., Jomeen, J., \& Galvin, R. (2018). Irish general practitioners' view of perinatal mental health in general practice: A qualitative study. BMC Family Practice., 19. https://doi. org/10.1186/s12875-018-0884-5.

O'Connell, M. A. (2019). Preventing, recognising, and responding to fear of childbirth and birth trauma. In The BMJ., 12279. https://doi.org/ 10.1136/bmj.12279.

Persson, E. K., Kvist, L. J., \& Ekelin, M. (2018). Midwifery students' experiences of learning through the use of written reflections - An interview study. Nurse Education in Practice, 30, 73-78. https://doi. org/10.1016/j.nepr.2018.01.005.

Petit-Steeghs, V., Lips, S. R., Schuitmaker-Warnaar, T. J., \& Broerse, J. E. W. (2019). Client-centred maternity care from women's perspectives: Need for responsiveness. Midwifery., 74, 76-83. https://doi. org/10.1016/j.midw.2019.03.016

Pilkenton, D., Collins, M. R., \& Holley, S. (2015). Teaching labor : An Interprofessional Simulation. In Journal of Midwifery and Women's Health. https://doi.org/10.1111/jmwh.12373.

Renfrew, M. J., McFadden, A., Bastos, M. H., Campbell, J., Channon, A. A., Cheung, N. F., Silva, D. R. A. D., Downe, S., Kennedy, H. P., 
Malata, A., McCormick, F., Wick, L., \& Declercq, E. (2014). Midwifery and quality care: Findings from a new evidenceinformed framework for maternal and newborn care. In The Lancet., 384, 1129-1145. https://doi.org/10.1016/S0140-6736(14) 60789-3.

Rijnders, M., Baston, H., Schönbeck, Y., Van Der Pal, K., Prins, M., Green, J., \& Buitendijk, S. (2008). Perinatal factors related to negative or positive recall of birth experience in women 3 years postpartum in the Netherlands. Birth., 35, 107-116. https://doi.org/10. 1111/j.1523-536X.2008.00223.x.

Sando, D., Abuya, T., Asefa, A., Banks, K. P., Freedman, L. P., Kujawski, S., Markovitz, A., Ndwiga, C., Ramsey, K., Ratcliffe, H., Ugwu, E. O., Warren, C. E., \& Jolivet, R. R. (2017). Methods used in prevalence studies of disrespect and abuse during facility based childbirth: Lessons learned Prof. Suellen Miller. In Reproductive Health. https://doi.org/10.1186/s12978-017-0389-z.

Shakartzi, H., Wenren, L., Fernandes, S., Marino, R., Meade, M., PierreJoseph, N., Rodrigues, D., St Omer Roy, N., Valle, E., \& Abbott, J. F. (2018). DREAM: Empowering preclinical medical students with labor support. MedEdPORTAL : The Journal of Teaching and Learning Resources. https://doi.org/10.15766/mep 2374-8265. 10665.

Simpson, M., \& Catling, C. (2016). Understanding psychological traumatic birth experiences: A literature review. In Women and Birth., 29, 203-207. https://doi.org/10.1016/j.wombi.2015.10.009.

Sorenson, D. S., \& Tschetter, L. (2010). Prevalence of negative birth perception, disaffirmation, perinatal trauma symptoms, and depression among postpartum women. Perspectives in Psychiatric Care., 46, 14-25. https://doi.org/10.1111/j.1744-6163.2009.00234.x.

Stoll, K., Fairbrother, N., Carty, E., Jordan, N., Miceli, C., Vostrcil, Y., \& Willihnganz, L. (2009). "it's all the rage these days": University students' attitudes toward vaginal and cesarean birth. Birth, 36(2), 133-140. https://doi.org/10.1111/j.1523-536X.2009.00310.x.

Stramrood, C. A. I., Paarlberg, K. M., Huis In'T Veld, E. M. J., Berger, L. W. A. R., Vingerhoets, A. J. J. M., Weijmar Schultz, W. C. M., \& Van Pampus, M. G. (2011). Posttraumatic stress following childbirth in homelike-and hospital settings. Journal of Psychosomatic Obstetrics and Gynecology, 32, 88-97. https://doi.org/10.3109/ 0167482X.2011.569801.

Thompson, S. M., Nieuwenhuijze, M. J., Low, L. K., \& De Vries, R. (2019). Creating guardians of physiologic : The development of an educational initiative for student midwives in the Netherlands. Journal of Midwifery and Women's Health. https://doi.org/10. 1111/jmwh.12999. van Dinter-Douma, E. E., de Vries, N. E., Aarts-Greven, M., Stramrood, C. A. I., \& van Pampus, M. G. (2018). Screening for trauma and anxiety recognition: Knowledge, management and attitudes amongst gynecologists regarding women with fear of childbirth and postpartum posttraumatic stress disorder. Journal of MaternalFetal and Neonatal Medicine., 33, 2759-2767. https://doi.org/10. 1080/14767058.2018.1560409.

Wagner, M. (2001). Fish can't see water: The need to humanize birth. International Journal of Gynecology \& Obstetrics, 75(SUPPL. 1), S25-S37. https://doi.org/10.1016/S0020-7292(01)00519-7.

Warren, C. E., Njue, R., Ndwiga, C., Abuya, T., Kabo, J. W., Suellen Millera AndreLalonde, McMahon, S. A., George, A. S., Chebet, J. J., Mosha, I. H., Mpembeni, R. N. M., Winch, P. J., Kendall, T., Downe, S., World Health Organization, Wesson, J., Hamunime, N., Viadro, C., Carlough, M., ... Access, O. (2018). WHO recommendations: Intrapartum care for a positive childbirth experience. $B M C$ Pregnancy and Childbirth. https://doi.org/10.5935/1676-4285. 20155067.

Watanabe, T., Knobel, R., Suchard, G., Franco, M. J., D'orsi, E., Consonni, B., \& Consonni, M. (2012). Medical students' personal choice for mode of delivery in Santa Catarina, Brazil: a cross-sectional, quantitative study. https://doi.org/10.1186/1472-6920-12-57.

Werner, A., \& Malterud, K. (2003). It is hard work behaving as a credible patient: Encounters between women with chronic pain and their doctors. Social Science and Medicine, 57(8), 1409-1419. https:// doi.org/10.1016/S0277-9536(02)00520-8.

World Health Organization. (2015). The prevention and elimination of disrespect and abuse during facility-based childbirth: WHO statement. World Health Organization., 15, e156-e158. https://doi.org/ 10.1111/j.1756-185X.2011.01636.x.

Yildiz, P. D., Ayers, S., \& Phillips, L. (2017). The prevalence of posttraumatic stress disorder in pregnancy and after birth: A systematic review and meta-analysis. In Journal of Affective Disorders (Vol. 208, pp. 634-645). Elsevier B.V. https://doi.org/10.1016/j.jad.2016. 10.009 .

Yin, Y., Li, J., Lu, H., Yao, J., \& Hou, R. (2018). Essential competencies for three grades of midwives in China. International Journal of Nursing Sciences., 5, 18-23. https://doi.org/10.1016/j.ijnss.2017. 12.010 .

Publisher's Note Springer Nature remains neutral with regard to jurisdictional claims in published maps and institutional affiliations. 